\title{
EDITORIAL
}

\section{REVIVING FORENSIC SPECIALITIES IN SRI LANKA}

\author{
Dr. Induwara Gooneratne
}

\section{Department of Forensic Medicine, University of Peradeniya, Sri Lanka}

Forensic Expert opinions have been useful unarguably worldwide to establish legal probanda, which otherwise would have been difficult, especially when eye witnesses are unavailable. This means that such forensic opinions can be of help to increase the probability of a fact in issue to be logically and of course legally in existence. Over the years, it is seen that many different forensic sciences contribute significantly to increase the evidentiary and probative value so that whichever the side that embraces the opinion can comfortably maintain the line of argument towards their own ultimate probanda. Despite many criticisms they may have about forensic opinions ranging from them being ‘unrealistic, unsubstantiated, opinionated, judgmental, confusing, disputed, logically implausible and the like', their use and contribution remains high.

While appreciating the many different forensic disciplines available world over today, this paper highlights a few key forensic domains that are essential to a country for its justice process. An equally significant aspect to mention here is that most of these essential disciplines in forensics are not developed except of course for forensic medicine and pathology. Accordingly, this paper argues that Sri Lanka must pay attention to establish these disciplines to ensure justice and quality of law enforcement.

Forensic Medicine and Pathology is comparatively well established in Sri Lanka. It has its own well organized undergraduate teaching programs, organized post graduate training programs, boards of studies, a College and established departments in universities and specialized JMOs (Judicial Medical Officers) in hospitals. For many years this discipline has been in existence, of course, contributing immensely to ensure justice. However, most forensic medical units run with basic facilities and poor infra structure. Modern facilities such as emerging technology, specialized approaches in histopathology such as immune histochemistry or molecular pathology and biochemistry would be quite essential to upgrade their services in par with modern forensic investigations.

Given the growing demand and interest in Forensic Dentistry among many, Sri Lanka has introduced a master's degree program offered by University of Peradeniya and then another postgraduate program set to be offered from University of Colombo through the Post Graduate Institute of Medicine. These post graduate programs are in addition to 
the teaching program offered in forensic dentistry at undergraduate level at University of Peradeniya. Notwithstanding the introduction of these academic programs, the commitment stake holders demonstrate to develop this discipline is not satisfactory. Although there are established units for forensic dentistry in Colombo and in Peradeniya, the infrastructure and facilities remain minimal.

Next important aspect is forensic Sciences. Despite the availability of a few trained personnel in the Government Analyst department, this country as a policy does not produce forensic scientists continuously. There are no academic programs in forensic sciences although a couple of sessions are taught in several degree courses. This means that the forensic sciences training programs are not well organized nor are they very specific in Sri Lanka. Officers in Government Analyst department become experts, ex-officio due to the recognition of this department by the law. The structure of the law is such that it more or less prevents budding experts in other units other than the government analyst department. Due to the very nature and tradition of the law enforcement relying heavily on the Government Analyst department owing to the recognition it has based on the substantive law, experts in other units for example in universities are sidelined although they may have acquired highly specialized qualifications and experience. There is a requirement at national level to provide defense opinions on all forensic aspects for example drugs or toxicology - and unfortunately in Sri Lanka many seem to solely rely on the Government Analyst's report without it been reviewed by independent experts.
This culture requires change to promote the development of science, fairness and justice. Fingerprint analysis is no different. The law itself identifies a police personal to be an expert while a university academic with high level of training and research in the field of forensic fingerprints may be sidelined.

Although there are a few people emerging with expertise with forensic entomology, anthropology, and the like there is no overall unit that can house all of them with a high level of coordination to facilitate a proper teamwork for forensic investigations. Forensic ballistics, forensic computing, forensic veterinary medicines are other areas that require further commitment, training, research, development and organization.

In order to develop these to full functioning entities in Sri Lanka, people with required qualifications should be given specialized training locally and aboard, familiarize them with forensic investigations and teamwork, teach them relevant law and providing expert opinions to court or law enforcement. This requires organized training programs, post graduate degrees, legal and government recognition of these disciplines, personnel and then a place where they can all converge as a team. Perhaps it may be a good idea to develop these disciplines in universities and converge them into a common centre when a case emerges which warrant their expertise. Certainly, research in all these areas is minimal in Sri Lanka. Most publications are case reports which are considered to be at the very bottom of research hierarchies. In short, these experts must develop research while proving service function. 
My contention is to identify these key forensic disciplines as essential for justice administration and develop organised training programs at post graduate levels coupled with long term training at a foreign unit for the trainee and then utilise their services when and where necessary to deliver justice to the people of Sri Lanka. Indeed, it is important that their job security is maintained, terms of reference are designed, quality control mechanisms are in place and their discipline/expertise is recognised by law. 